\title{
Farmacovigilância das Vacinas contra a COVID-19 Durante a Gravidez e a Amamentação
}

\section{Pharmacovigilance of COVID-19 Vaccines in Pregnant and Lactating Women}

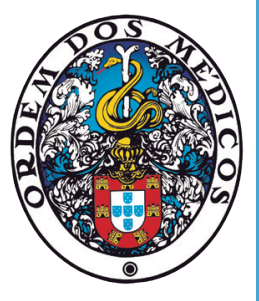

\author{
Ana Marta SILVA $\triangle^{1,2,3}$, Inês RIBEIRO-VAZ11,2,3, Renato FERREIRA-DA-SILVA ${ }^{1,2,3}$, Ricardo CRUZ-CORREIA ${ }^{2,3}$, \\ Jorge POLÓNIA ${ }^{1,3,4}$, João BERNARDES ${ }^{3,5}$ \\ Acta Med Port 2021 Dec;34(12):807-809 - https://doi.org/10.20344/amp.16762
}

Palavras-chave: Amamentação; Efeitos Colaterais e Reações Adversas Relacionados a Medicamentos; Farmacovigilância; Gravidez; SARS-CoV-2; Vacinas contra a COVID-19

Keywords: Breast Feeding; COVID-19 Vaccines; Drug-Related Side Effects and Adverse Reactions; Pharmacovigilance; Pregnancy; SARS-CoV-2

A pandemia provocada pelo SARS-CoV-2 conduziu a diferentes desafios em diversas áreas clínicas. Em obstetrícia, destacam-se a vigilância da gravidez e a assistência ao parto em contexto pandémico e, em particular, o aconselhamento sobre a vacinação durante a gravidez e a amamentação. O desenvolvimento das vacinas contra a COVID-19 trouxe esperança, uma vez que a vacinação é eficaz na prevenção da infeção pelo SARS-CoV-2 e na proteção contra formas graves da doença COVID-19. Contudo, trouxe também hesitação da população, nomeadamente em grupos especiais como é o caso das grávidas.

Segundo a evidência científica disponível à data, as mulheres grávidas não aparentam ter maior risco de serem infetadas com SARS-CoV-2 do que a população em geral. ${ }^{1}$ Como observado em mulheres não grávidas, existe uma maior proporção de mulheres grávidas com infeção assintomática por SARS-CoV-2. ${ }^{2}$ No entanto, alguns estudos indicam que a COVID-19 pode ser mais grave na muIher grávida, particularmente quando a infeção ocorre no terceiro trimestre ${ }^{2-4}$ sendo que a gravidade da doença em mulheres grávidas pode ser três vezes superior em relação à necessidade de recorrer aos cuidados intensivos [10,5 vs $3,9 / 1000$ casos; $\left.R_{a}=3,0 ; I_{95 \%}=(2,6-3,4)\right]$ e à ventilação mecânica [2,9 vs 1,1/1000 casos; $R_{\mathrm{a}}=2,9 ; \mathrm{IC}_{95 \%}=(2,2$ $-3,8)$ ] quando comparado com mulheres não grávidas da mesma idade. ${ }^{4}$ Os fatores de risco para o desenvolvimento de doença grave são a idade (especialmente se igual ou superior a 35 anos), a obesidade e outras comorbilidades, como hipertensão, diabetes ou presença de duas comorbilidades em simultâneo. ${ }^{2,4}$

Relativamente ao risco para o feto, ainda não existem evidências claras de que o SARS-CoV-2 tenha capacidade de atravessar a placenta e infetar o feto. ${ }^{5,6}$ Existem porém alguns casos em que o tecido placentário e as membra- nas testaram positivo a SARS-CoV- $2,{ }^{5}$ e outros, mais raros, com suspeita de infeção in utero ou infeção neonatal, ${ }^{7}$ que poderão ter resultado de testes falsos positivos ou exposição ao vírus após o parto.

O leite materno oferece proteção contra muitas doenças e existem poucas contraindicações para a amamentação, ${ }^{8}$ não sendo provável que o leite materno constitua uma fonte de infeção por SARS-CoV-2..$^{9,10}$ Foram detetadas em algumas amostras de leite materno com resultado positivo para material genético do SARS-CoV-2, mas não foi detetado nenhum vírus competente de replicação., ${ }^{9,10}$ Desta forma, a suspeita ou confirmação de infeção materna por SARS-CoV-2 durante a amamentação não é considerada uma contraindicação. No entanto, existem cuidados de higiene indispensáveis (p.e.: higiene das mãos e uso de máscara) que a mãe deve ter para diminuir o risco de transmissão ao recém-nascido, uma vez que este pode ser transmitido através de gotículas durante o contacto próximo com o mesmo.

As vacinas contra a COVID-19 aprovadas pela Agência Europeia do Medicamento (EMA) cumpriram todas as etapas preconizadas no desenvolvimento de qualquer vacina para a obtenção da autorização de introdução no mercado. À semelhança do que é prática corrente no âmbito da segurança em ensaios clínicos, grupos especiais como crianças, idosos e grávidas tendem a ser excluídos destes estudos ou, quando incluídos, apenas sob condições altamentes controladas. Os ensaios clínicos promovidos pela Pfizer, Moderna, AstraZeneca e Johnson \& Johnson para as vacinas contra a COVID-19 excluíram as grávidas e mulheres a amamentar. Os estudos pré-clínicos conduzidos em animais não revelaram eventuais efeitos negativos no embrião ou no feto, ou mesmo na mulher grávida. A informação recolhida em estudos conduzidos em animais, em mulheres

\footnotetext{
1. Unidade de Farmacovigilância do Porto. Faculdade de Medicina. Universidade do Porto. Porto. Portugal.

2. Departamento de Medicina da Comunidade, Informação e Decisão em Saúde. Faculdade de Medicina. Universidade do Porto. Porto. Portugal.

3. CINTESIS - Centro de Investigação em Tecnologias e Sistemas de Saúde. Porto. Portugal.

4. Departamento de Medicina. Faculdade de Medicina. Universidade do Porto. Porto. Portugal.

5. Departamento de Ginecologia-Obstetrícia e Pediatria. Faculdade de Medicina. Universidade do Porto. Porto. Portugal.

$\triangle$ Autor correspondente: Ana Marta Silva. ammsilva@med.up.pt

Recebido: 22 de junho de 2021 - Aceite: 06 de setembro de 2021 - First published: 03 de novembro de 2021 - Online issue published: 02 de dezembro de 2021 Copyright $\odot$ Ordem dos Médicos 2021
} 
grávidas e em pequenos estudos prospetivos coorte não revelaram efeitos negativos no embrião ou no feto, tendo, pelo contrário, identificado resposta imune materna e transferência de anticorpos maternos para o feto através da placenta, e para o leite materno, conferindo ao recém-nascido imunização passiva contra o SARS-CoV-2. ${ }^{11,12}$

É premente recolher dados clínicos de exposição às diferentes vacinas contra a COVID-19 na gravidez e durante a amamentação, não só pela escassez de dados sobre a sua utilização nestes grupos especiais, como também pelo contributo que estes dados podem dar à tomada de decisões.

Atualmente, várias entidades, nomeadamente a Organização Mundial de Saúde (OMS), o Centers for Disease Control and Prevention (CDC), o American College of Obstetricians and Gynecologists (ACOG), a Society for Maternal-Fetal Medicine (SMFM) e a Direção Geral de Saúde (DGS) recomendam a vacinação da grávida e da mulher a amamentar. Mais concretamente, a Norma $n^{\circ} 002 / 2021$ da DGS recomenda a vacinação na grávida com 16 ou mais anos de idade e na mulher a amamentar, não sendo necessário a declaração médica nas seguintes situações: (1) a partir das 21 semanas de gestação, após a realização da ecografia morfológica, não existindo idade gestacional limite para o início da vacinação, (2) após um intervalo mínimo de 14 dias em relação à administração de outras vacinas, tais como a vacina contra a tosse convulsa (Tdpa) e a vacina contra a gripe, e (3) em caso de amamentação, já que não constitui contraindicação para a vacinação.

Nenhuma das vacinas comercializadas contêm vírus com capacidade para se replicar, e, por isso, não causam doença. Embora possam desencadear reações adversas associadas à ativação do sistema imune (p.e.: mialgia, cefaleia, fadiga, pirexia ou reações no local de vacinação), os especialistas acreditam que é improvável que coloquem em risco as grávidas, o feto e as lactentes. No entanto, à medida que a ciência evolui e com o aumento da evidência científica disponível sobre este assunto, as recomendações poderão vir a ser ponderadas e alteradas. O principal benefício da vacinação na grávida poderá ser a redução da incidência da doença grave.

No momento da decisão sobre a vacinação contra a COVID-19 durante a gravidez, existem alguns fatores a ter em consideração, nomeadamente: (1) risco de exposição ao SARS-CoV-2, (2) fatores de risco e (3) nível de ansiedade. Quanto ao grau de exposição, deve ser ponderada a exposição ao agente infecioso durante a gravidez, i.e., pela frequência de ambientes de baixo, moderado ou alto risco de exposição ao vírus e a facilidade de implementação de medidas para o mitigar. Relativamente aos fatores de risco, devem ser analisadas características maternas, tais como a idade materna, excesso de peso (IMC $\geq 25 \mathrm{~kg} /$ $\mathrm{m}^{2} \mathrm{e}<30 \mathrm{~kg} / \mathrm{m}^{2}$ ) ou obesidade (IMC $\geq 30 \mathrm{~kg} / \mathrm{m}^{2}$ ) e doenças pré-existentes, como por exemplo, a hipertensão arterial ou a diabetes (tipo 1 e 2). Por último, deve ser ponderado se a vacinação irá introduzir um nível de ansiedade excessivo na mulher grávida com potencial impacto no desfecho da gravidez.

No que concerne à vacinação na mulher a amamentar, não é expectável, dada a tecnologia envolvida na produção das vacinas, a existência de reações adversas no lactente, não sendo aconselhável suspender a amamentação se a mulher for vacinada, conforme referido nas Normas $n^{\circ}$ 021/2020, n 001/2021, n 003/2021 e n 004/2021 da DGS. A importância clínica destas questões foi recentemente apoiada por um estudo publicado no American Journal of Obstetrics and Gynecology, que encontrou evidência da passagem de anticorpos para o recém-nascido por exposição indireta, i.e., através do leite materno de mulheres que foram vacinadas com tecnologia de mRNA contra a COVID-19,11 oferecendo imunização passiva.

As vacinas sob discussão neste artigo encontram-se com autorização condicional de introdução no mercado, que é uma ferramenta pragmática para a aprovação rápida de um medicamento e que responde a uma necessidade clínica (ainda sem alternativa). Isto significa que estas vacinas estão sob permanente escrutínio, com publicação de relatórios periódicos de segurança e informação sobre dados de exposição (nomeadamente em grupos especiais como grávidas e lactantes).

Atualmente já existem dados, ainda que limitados, de exposição às vacinas contra a COVID-19 durante a gravidez e amamentação reportados em Portugal e na Europa (Tabela 1), monitorizados pelos sistemas de farmacovigilância. Contudo, permanecem sem resposta consensual e/ou cientificamente fundamentada algumas questões: (1) Qual a vacina mais indicada para a grávida? (2) Em que trimestre é mais aconselhado administrar a vacina? (3) O nível de imunidade conferida pela vacina na mulher grávida ou a amamentar é suficiente para impedir a infeção pelo vírus SARS-CoV-2? (4) Qual a duração da imunidade na mãe e no lactante? (5) Será que o risco de reações

Tabela 1 - Número de casos de exposição a vacinas contra a COVID-19 durante a gravidez e amamentação reportados em Portugal e na Europa. Dados recolhidos a 20/06/2021.

\begin{tabular}{lcccc} 
& \multicolumn{2}{c}{ Portugal } & \multicolumn{2}{c}{ Europa } \\
& Gravidez & Amamentação & Gravidez & Amamentação \\
\hline Comirnaty $^{\circ}$ & 33 & 3 & 347 & 145 \\
Spikevax $^{\odot}$ & 1 & 0 & 279 & 56 \\
Vaxzevria $^{\odot}$ & 7 & 11 & 283 & 1156 \\
COVID-19 Vaccine Janssen $^{\odot}$ & 0 & 0 & 14 & 4 \\
\hline
\end{tabular}

Fontes: Portal RAM; Eudravigilance 
adversas possíveis às vacinas é direta ou até inversamente proporcional à idade da grávida? (6) Será que a hipertensão gestacional e a diabetes gestacional agravam o risco de complicações da doença e/ou das vacinas? (7) Será que grávidas imunocomprometidas ou com patologia ativa possuem um risco aumentado de desenvolver complicações da doença e/ou das reações adversas às vacinas?

É com o objetivo de obter respostas a estas questões que os sistemas de farmacovigilância recolhem e monitorizam permanentemente informação sobre a exposição às vacinas contra a COVID-19 na gravidez e realizam o follow-up do recém-nascido e amamentação, possibilitando assim o desenvolvimento de bases de dados farmacoepidemiológicas. Todos os dados são cruciais, quer se trate de reações adversas pós-vacinação ou de casos de vacinação sem qualquer intercorrência. A informação pode ser comunicada através do Portal RAM, do Sistema Nacional de Farmacovigilância - INFARMED, I.P. (https://www.infarmed.pt/ web/infarmed/submissaoram). Para além desta recolha de informação pelos sistemas de farmacovigilância, a EMA está a promover estudos observacionais pós-autorização (post-authorisation safety studies) para avaliação de questões de segurança das vacinas nestes grupos populacio-

\section{REFERÊNCIAS}

1. Docherty $A B$, Harrison EM, Green CA, Hardwick HE, Pius R, Norman L, et al. Features of 20133 UK patients in hospital with covid-19 using the ISARIC WHO Clinical Characterisation Protocol: prospective observational cohort study. BMJ. 2020;369:m1985.

2. Allotey J, Stallings E, Bonet M, Yap M, Chatterjee S, Kew T, et al. Clinical manifestations, risk factors, and maternal and perinatal outcomes of coronavirus disease 2019 in pregnancy: living systematic review and meta-analysis on behalf of the PregCOV-19 Living Systematic Review Consortium. BMJ. 2020;370:m3320.

3. Khalil A, Kalafat E, Benlioglu C, O'Brien P, Morris E, Draycott T, et al. SARS-CoV-2 infection in pregnancy: a systematic review and metaanalysis of clinical features and pregnancy outcomes. EClinicalMedicine. 2020;25:100446

4. Zambrano LD, Ellington S, Strid P, Galang RR, Oduyebo T, Tong VT, et al. Update: of of reproductive age with laboratory-confirmed SARSCoV-2 infection by pregnancy status - United States, January 22October 3, 2020. MMWR Morb Mortal Wkly Rep. 2020;69:1641-7.

5. Resta L, Vimercati A, Cazzato G, Mazzia G, Cicinelli E, Colagrande A, et al. SARS-CoV-2 and placenta: new insights and perspectives. Viruses. 2021;13:723.

6. Egloff C, Vauloup-Fellous C, Picone O, Mandelbrot L, Roques P. Evidence and possible mechanisms of rare maternal-fetal transmission nais e para o estudo do grau de imunidade conferido por estas vacinas às grávidas, recém-nascidos e lactentes.

Atualmente, considera-se que os benefícios das vacinas contra a COVID-19 superam os potenciais riscos de desenvolvimento de reações adversas às mesmas, bem como dos riscos inerentes à infeção por SARS-CoV-2 na grávida e na mulher a amamentar.

\section{CONTRIBUTO DOS AUTORES}

Todos os autores contribuíram de igual forma para a conceção/desenho, rascunho, revisão e aprovação final, e concordam em ser responsáveis por todos os aspetos do trabalho.

\section{CONFLITOS DE INTERESSE}

Os autores declaram não ter conflitos de interesses relacionados com o presente trabalho.

\section{FONTES DE FINANCIAMENTO}

Este trabalho não recebeu qualquer tipo de suporte financeiro de nenhuma entidade no domínio público ou privado.

of SARS-CoV-2. J Clin Virol. 2020;128:104447.

7. Ghema K, Lehlimi M, Toumi H, Badre A, Chemsi M, Habzi A, et al Outcomes of newborns to mothers with COVID-19. Infect Dis Now. 2021;51:435-9.

8. World Health Organization. Promoting effective perinatal care 2002 essential newborn care and breastfeeding training modules. WHO Regional Office for Europe. [consultado 2021 jul 26]. Disponível em: https://apps.who.int/iris/bitstream/handle/10665/107481/e79227. pdf?sequence=1\&isAllowed=y.

9. Centeno-Tablante E, Medina-Rivera M, Finkelstein JL, Rayco-Solon P, Garcia-Casal MN, Rogers L, et al. Transmission of SARS-CoV-2 through breast milk and breastfeeding: a living systematic review. Ann N Y Acad Sci. 2021;1484:32-54.

10. Bhatt $H$. Should COVID-19 mother breastfeed her newborn child? A literature review on the safety of breastfeeding for pregnant women with COVID-19. Curr Nutr Rep. 2021;10:71

11. Gray KJ, Bordt EA, Atyeo C, Deriso E, Akinwunmi B, Young N, et al. COVID-19 vaccine response in pregnant and lactating women: a cohort study. Am J Obstet Gynecol. 2021;225:303.E1-17.

12. Collier AY, McMahan K, Yu J, Tostanoski LH, Aguayo R, Ansel J, et al. Immunogenicity of COVID-19 mRNA vaccines in pregnant and lactating women. JAMA. 2021;325:2370-80. 